\title{
European clinical guidelines for Tourette syndrome and other tic disorders-version 2.0. Part IV: deep brain stimulation
}

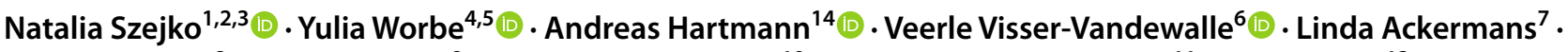

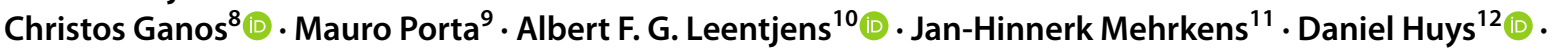 \\ Juan Carlos Baldermann ${ }^{12}$ (D) Jens Kuhn ${ }^{12,13}$ (D) $\cdot$ Carine Karachi $^{5,14,15} \cdot$ Cécile Delorme $^{14}$ (D) Thomas Foltynie $^{16}$ (i) \\ Andrea E. Cavanna ${ }^{17}$ (D) Danielle Cath ${ }^{18,19}$. Kirsten Müller-Vahl ${ }^{20}{ }^{(1)}$
}

Received: 7 March 2021 / Accepted: 15 September 2021 / Published online: 4 October 2021

(c) The Author(s) 2021

\begin{abstract}
In 2011 the European Society for the Study of Tourette Syndrome (ESSTS) published its first European clinical guidelines for the treatment of Tourette Syndrome (TS) with part IV on deep brain stimulation (DBS). Here, we present a revised version of these guidelines with updated recommendations based on the current literature covering the last decade as well as a survey among ESSTS experts. Currently, data from the International Tourette DBS Registry and Database, two meta-analyses, and eight randomized controlled trials (RCTs) are available. Interpretation of outcomes is limited by small sample sizes and short follow-up periods. Compared to open uncontrolled case studies, RCTs report less favorable outcomes with conflicting results. This could be related to several different aspects including methodological issues, but also substantial placebo effects. These guidelines, therefore, not only present currently available data from open and controlled studies, but also include expert knowledge. Although the overall database has increased in size since 2011, definite conclusions regarding the efficacy and tolerability of DBS in TS are still open to debate. Therefore, we continue to consider DBS for TS as an experimental treatment that should be used only in carefully selected, severely affected and otherwise treatment-resistant patients.
\end{abstract}

Keywords Tics - Tourette syndrome · Deep brain stimulation · Treatment · Guidelines · European Society for the Study of Tourette Syndrome (ESSTS)

\section{Introduction}

Tourette syndrome (TS) is a chronic motor and vocal tic disorder. The prevalence of TS in general population is estimated at $0.3-1 \%$ [1-3]. After the onset, usually at the age of about $4-6$ years, tics tend to have a waxing and waning course over the years and generally reach a maximum severity around 12 years [4]. In the vast majority of patients, thereafter tics decrease during adolescence or early adulthood and overall have a favorable prognosis. In those patients suffering from disabling tics, behavioral and/or

This article is part of the focused issue "Update of the European clinical guidelines for Tourette Syndrome and other tic disorders".

Natalia Szejko

natalia.szejko@wum.edu.pl

Extended author information available on the last page of the article pharmacotherapy is recommended as first line treatments [5-8].

A minority of patients experiences a persistent course and does not benefit from well-established treatments and/ or experience serious side effects such as significant weight gain, hyperprolactinemia, somnolence and tiredness [9]. To date, there is no generally established definition available for "treatment refractoriness" and exact number of "treatmentrefractory" patients is unknown [10-12]. However, there is broad agreement that various types of treatments in adequate doses, frequency, and duration should have been used before classifying a patient as otherwise "treatment-refractory". Surgical treatment with deep brain stimulation (DBS) should be taken into consideration only in patients with severe and otherwise treatment-refractory tics. In most of these severely affected patients, psychiatric comorbidity such as attentiondeficit/hyperactivity disorder (ADHD), obsessive-compulsive symptoms (OCS) or disorder (OCD), depression, anxiety, and self-injurious behavior (SIB) is present that often 
impairs patients' quality of life more than the tics [13-16]. Thus, before considering DBS for tics in TS, the best possible treatment of psychiatric symptoms-notably obsessions, compulsions and depression - should have been carried out $[17,18]$.

In TS, ablative surgery with prefrontal lobotomy was first performed in 1955 [19]. The first surgical treatment using the thalamus as a target was undertaken in 1970 by Hassler and Dieckmann [20], who performed thalamotomy in the centromedial-parafascicular complex (CM-Pf) and nucleus ventro-oralis internus (Voi) in three patients, which resulted in a tic reduction of $70-100 \%$ [21]. Subsequently, Babel et al. [22] reported tic reduction in 14 of 17 patients after ventriculography-based stereotactic zona incerta (ZI) and ventrolateral/lamella medialis thalamotomy (VL/LM). However, in a large number of patients postoperative complications occurred including (transient or permanent) cerebellar ataxia, dysarthria, dystonia, and hemiballism. Finally, in 1999 [23] thalamic deep brain stimulation (DBS) was performed for the first time in three otherwise treatment-refractory adult patients with TS. Subsequently, several other targets have been suggested.

In 2011, the European Society for the Study of Tourette Syndrome (ESSTS) published its first European clinical guidelines on the treatment of TS with part IV on DBS [18]. Here, we provide our updated guidelines with recommendations for the clinical practice of DBS in TS based not only on the evidence obtained over the past decade, but also on expert knowledge including results from a survey among a large number of ESSTS experts.

\section{Methods}

For the current version of part IV of the European clinical guidelines, a literature search was carried out. The aim was to identify relevant research on efficacy and safety of DBS for TS published between January 2011 and August 2021. Our systematic approach was based on the search in PubMed, Ovid, Web of Science, Embase, and APA Psych Info conducted on March 2020 and again on August 27, 2021. We searched for articles reporting about DBS in TS using the search terms "tics" AND/OR "Tourette" AND/ OR "deep brain stimulation" AND/OR "DBS". Reviews and meta-analyses in the area were further searched for relevant citations. In addition, the reference lists of the articles identified were reviewed for additional studies. In addition to the studies identified through systematic review, to make the publication list as comprehensive as possible, studies still in press and not officially published were added by the authors (i.e. through precedent knowledge about relevant publications). The methodology of the ESSTS survey is presented in a summary paper in the current issue of this journal [24].

\section{Review of the literature (based on search of studies on DBS between 1970 and August 2021)}

Preliminary note: The available evidence for DBS in TS is still very limited. Available evidence is based on few small randomized controlled trials (RCTs), open uncontrolled case reports and case series, registries, and meta-analyses. It is important to note that data largely overlap and results from one single patient may be included in more than one report. To give the best possible overview and comparability, we report data depending on the study design. For more detailed results we refer to the original publications.

When the first version of the ESSTS DBS guidelines was published in 2011 [18], only 3 RCTs were available, each including 1 to 5 patients [25-27] with altogether nine patients. In addition, open and uncontrolled reports covering a total of 63 patients were published, which reported beneficial outcomes with moderate to marked tic improvement in the vast majority of patients $(59 / 63$ patients). Since this review, five subsequent RCTs have been published, resulting in a total of 62 patients in all RCTs. Thus, until today there is still only a total of eight RCTs available including a maximum of 17 patients [25-32]. A summary of these studies is presented in Table 1. In addition, data from the International Deep Brain Stimulation Database and Registry including 185 patients (published in 2018 [33]), one retrospective analysis on long-term follow-up in 110 patients (published in 2019 [34]), and two meta-analyses (published in 2016 and 2018) including 58 [35] and 156 [36] patients were published. In addition, data from several further open uncontrolled studies and case series were published including 2 to 123 subjects as well as more than 100 single case reports (for summary see Table 2).

\section{Randomized controlled trials}

To date, since 1999, 8 RCTs examining efficacy and safety of DBS in TS have been published with a total of 62 patients (for further details including target, treatment duration, effects on tics and comorbidities see Table 1). However, results are still limited by small sample sizes (ranging from 1 to 17 patients). The first trial by Houeto et al. [25] included only one patient who was treated with bilateral high frequency stimulation of the centre median nucleus/parafascicular complex (CM-Pf), the internal 


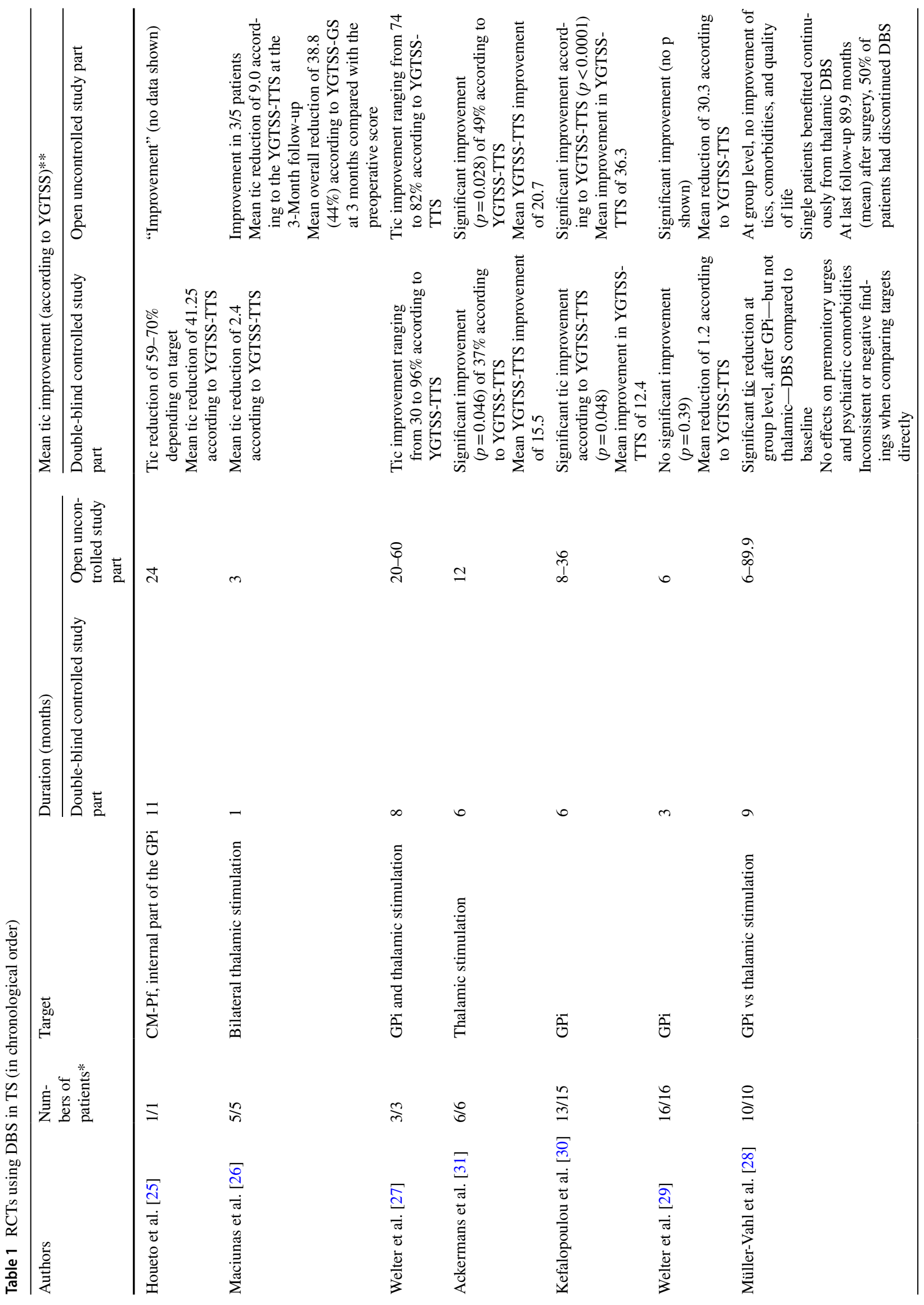




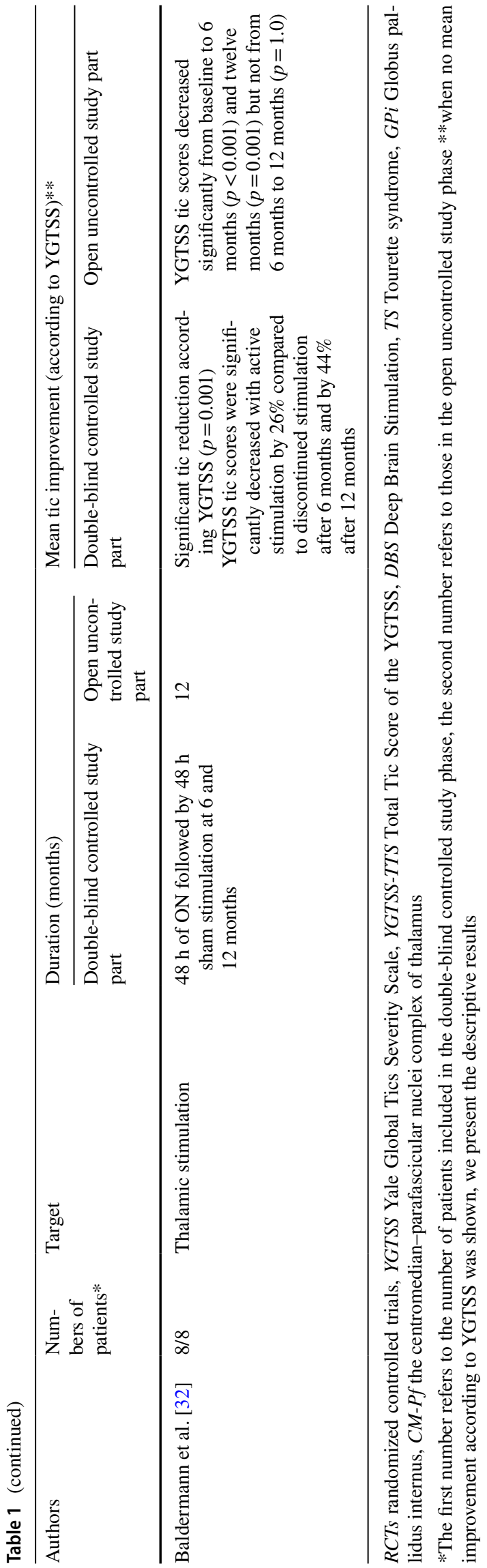

part of the globus pallidus (GPi), or both. Stimulation of either target resulted in tic improvement of $70 \%$, markedly ameliorated coprolalia, and eliminated SIB. In another double-blind crossover trial of bilateral thalamic DBS in five adults with TS [26] a statistically significant $(p<0.03)$ reduction in the modified Rush Video-Based Rating Scale was identified and motor and vocal tics significantly improved according to the Yale Global Tic Severity Scale Total Tic Score (YGTSS-TTS). Welter et al. [27] included three patients with severe, medically refractory TS who received bilateral stimulation in the CM-Pf and the GPi. Both interventions resulted in significant improvement of tics ranging from 30 to $96 \%$. The two largest RCTs (both using GPi DBS) included 15 [30] and 17 [29] patients respectively, and demonstrated overall tic improvement during the blinded study phase of $15.3 \%(p=0.048)$ on the YGTSS-TTS in one study [29], but no improvement in the other (median tic reduction of $1.1 \%, p=0.39$ ) [30]. However, in both studies a significant improvement was reported at the end of the open-label phase after several months (6-48 months) with a tic reduction of $40.1 \%$ and $69.5 \%$, respectively $[29,30,95]$. In the third largest RCT [28] (comparing efficacy and safety of bilateral DBS of CM-Voi versus posteroventral lateral pvl) Gpi versus sham stimulation), 10 patients were included and GPi DBS $(p=0.05)$-but not thalamic DBS $(p=0.18)$-resulted in a significant tic reduction compared to baseline, but had no effect on premonitory urges and psychiatric comorbidities. Direct comparisons of both targets to sham stimulation resulted in inconsistent or negative findings. During follow-up, at group level, no improvement of tics, comorbidities, and quality of life was demonstrated, while single patients benefitted continuously from thalamic DBS. In another RCT (using the CM-Voi of the thalamus), six patients were included and a significant tic reduction of $37 \%$ was described in the blinded phase $(p=0.046)$ and of $49 \%(p=0.028)$ after one year of open label phase [31]. Finally, in 2021 Baldermann et al. [32] published results of their RCT in which eight patients with TS were included. The authors investigated the course of tic severity, comorbidities and quality of life during thalamic stimulation $(\mathrm{Cm}-\mathrm{Voi})$. The patients were assessed at baseline, after 6 months and 12 months after the surgery in the open label phase. Double-blind phase consisted of sham-controlled periods that took place at 6 and 12 months after the implantation and the patients received $48 \mathrm{~h}$ ongoing DBS (ON) followed by $48 \mathrm{~h}$ with sham stimulation (OFF) or vice versa in a crossover design. In double blind phase, significant tic reduction according to YGTSS $(p=0.001)$ occurred. In particular, the YGTSS tic scores were significantly decreased with active stimulation by $26 \%$ compared to discontinued stimulation after 6 months and by $44 \%$ after 12 months. In open label phase YGTSS tic 
Table 2 Published case reports and other open uncontrolled studies using DBS in patients with TS

\begin{tabular}{lll}
\hline Single case reports & & \\
\hline $\mathrm{N}$ of studies & $N$ (patients) & References \\
\hline 35 & 1 & {$[23,37-70]$} \\
\hline Case series & & \\
\hline $\mathrm{N}$ of studies & $N$ of patients (range) & References \\
25 & $2-55$ & {$[37,71,71-94]$} \\
\hline Open uncontrolled studies & & \\
\hline $\mathrm{N}$ of studies & $N$ of patients (range) & References \\
\hline 28 & $1-123$ & {$[34,95,95-122]$} \\
\hline
\end{tabular}

$D B S$ deep brain stimulation, TS Tourette syndrome

scores decreased significantly from baseline to 6 months $(p<0.001)$ and 12 months $(p=0.001)$ but not from 6 to 12 months $(p=1.0)$.

With respect to psychiatric comorbidity, only limited information is available. In 6 of 8 RCTs [25-27, 29, 30, 32], the effects of DBS (at different targets) on psychiatric symptoms are reported suggesting that DBS may also have beneficial effects on depression and/or anxiety. Effects on OCS and OCD varied, while there seems to be no effect on ADHD (for details see Table 3). It can be speculated that beneficial effects on depression and anxiety might be-at least in part-secondary due to improved tics. Furthermore, it has been speculated that assessment scales used for psychiatric symptoms might be less appropriate for use in patients with TS [31].

\section{The International Deep Brain Stimulation Database and Registry}

In 2018, data from a large international cohort were published based on the International Deep Brain Stimulation Database and Registry [33]. At the time, this registry included 185 patients with otherwise treatment-refractory TS, who underwent DBS implantation between 2012 and December 2016 at 31 institutions in 10 different countries (exact details about methodology of the data collection and analysis can be consulted in the paper by Martinez-Ramirez et al. [33]). The authors mainly focused on the efficacy of DBS in reducing tics at 6 and 12 months after DBS implantation as measured using the YGTSS-TTS) and the number and profile of adverse events (AEs) related to both surgery (such as infections and hemorrhage) and stimulation (such as paresthesias, bradykinesia, depression, and dystonia). In addition, sub-analyses were performed with respect to the target used [33]. The study reports that: (i) on average, DBS resulted in a tic improvement of $45.1 \%$ according to the
YGTSS-TTS, (ii) the overall rate of AEs was high (35.4\%) and most of the AEs were stimulation-related (30.8\%), whereas $3.8 \%$ were surgery-related and only $1.3 \%$ were device-related, (iii) the most frequently used target was the centro-median thalamic region ( $57.1 \%, 93 / 163$ patients), followed by the anteromedial part of the GPi $(25.2 \%, 41 / 163$ patients), the postero-ventrolateral part of the GPi (15.3\%, $25 / 163$ patients), and the anterior limb of the internal capsule (ALIC) $(2.5 \%, 4 / 163$ patients). Detailed data on the AEs are shown in subsequent paragraphs. Data obtained from other stimulation targets were not given. There was no evidence for superiority of a particular target [33]. Data from the same registry were complemented by a follow-up analysis published in 2019 [34]. Details are presented in the "Retrospective analysis on long-term follow-up" section.

\section{Meta-analyses}

To date, two meta-analyses have been published investigating efficacy and safety of DBS in adults (published in 2016) [36] and in children and youth [35] (published in 2018). Baldermann et al. [36] included 57 studies (both controlled and uncontrolled) with a total of 156 adult patients. Based on these data, DBS resulted in an average improvement of tics of $52.7 \%$ on the YGTSS-TTS (IQR $=40.74, p<0.001$ ). Analysis of data from controlled studies only (four studies with a total of 27 patients [25, 26, 30, 31]) favored "on stimulation" versus "sham stimulation" with a standardized mean difference of 0.96 (95\% CI 0.36-1.56).

With respect to the target (thalamus, posteroventrolateral part of the GPi, anteromedial part of the GPi, ALIC, and nucleus accumbens (NA), no significant differences were found in tic reduction, when analyzing data of all 57 studies together [36]. However, further analyses suggested that different patient groups benefitted differently from stimulation at different targets. In particular, thalamic stimulation was more effective when tics were less severe. In contrast, YGTSS-TTS after GPi DBS correlated positively with preoperative impairment score of the YGTSS, but not with the tic specific score (YGTSS-TTS). Regarding psychiatric comorbidities, Baldermann et al. [36] found a median reduction of OCD of $31.3 \%$ on the Yale-Brown Obsessive Compulsive Scale (Y-BOCS). Subgroup analysis did not show a difference in reduction of OCD symptoms between targets $(p=0.812)$. Moreover, there was a median improvement of mood of $38.9 \%$ (measured with the Beck Depression Inventory (BDI)). Again, subgroup analysis did not show differences between targets $(p=0.692)$.

In the second meta-analysis data on efficacy and safety of DBS specifically in children and youth (aged 12-21 years, mean age $17.9 \pm 2.7$ ) is summarized based on 21 studies including 58 cases. The authors report an average tic improvement of $57.5 \% \pm 24.6 \%$ [35]. Comorbid depression 


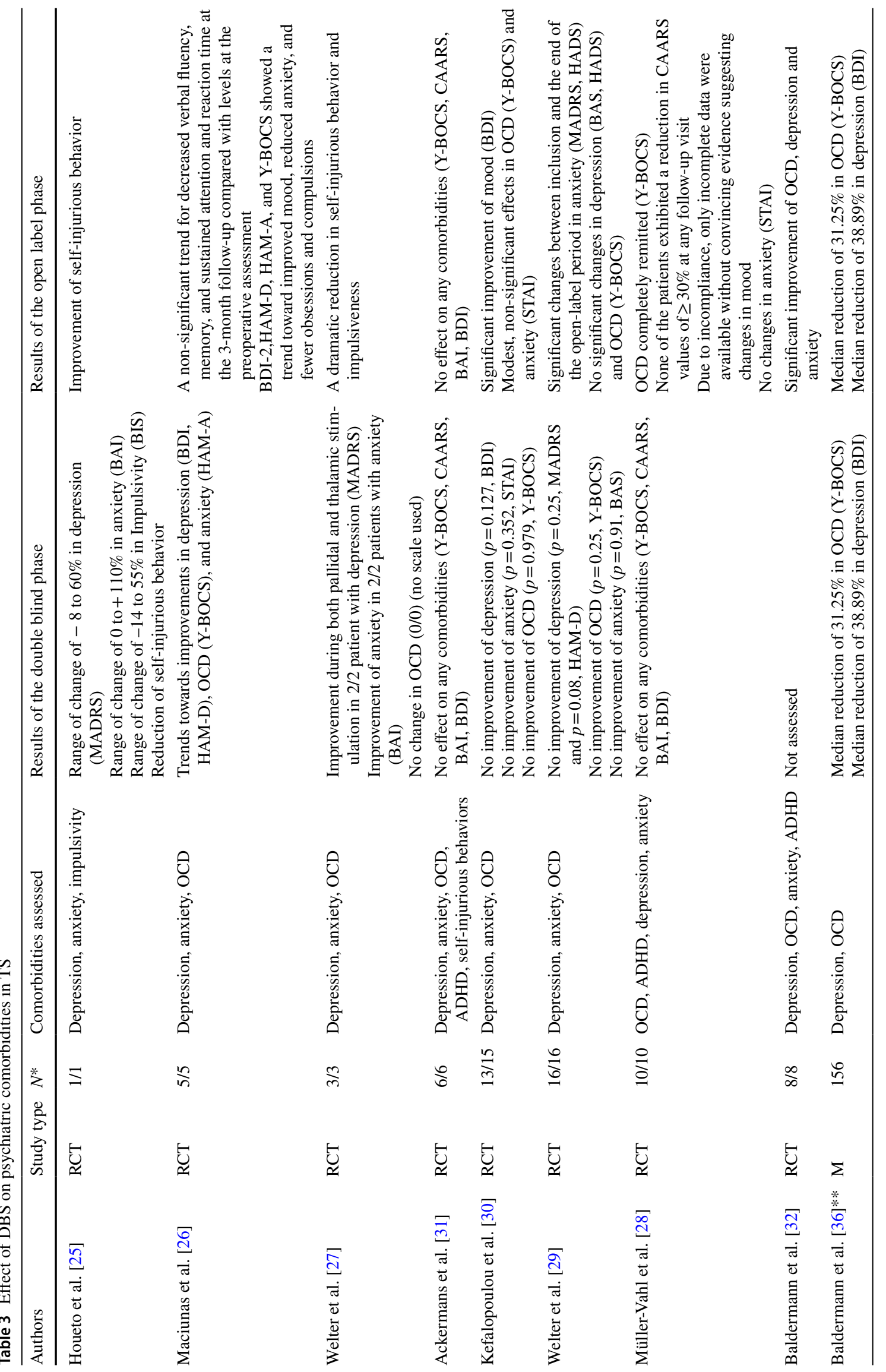


correlated negatively with outcome $(p<0.05)$. In patients with less severe tics greater improvements were evident following thalamic stimulation. More than one-quarter $(n=16$, $27.6 \%$ ) of participants experienced AEs, mostly mild in severity. For further details please consult the subsequent section dedicated to AEs. The authors' interpretation of the data is that in carefully selected children and youth with treatment refractory TS, DBS is an effective treatment for tics with a moderate safety profile. In none of the metaanalyses, any predictors were found that allow a prognosis of outcome after DBS.

\section{Retrospective analysis on long-term follow-up}

In 2019, Johnson et al. [34] published results of the largest retrospective analysis so far based on the International Deep Brain Stimulation Database and Registry involving 13 sites from North America (39 patients), Europe (63 patients) and Asia (21 patients). They assessed the effects of DBS in the long-term follow-up (up to 96 months) of 110 patients with TS, who were implanted in the CM-Pf and the CM/ Voi of the thalamus $(n=51)$, the GPi $(n=47)$, the NA/ALIC $(n=4)$ or combinations of these targets $(n=8)$. Similarly to Baldermann et al.'s meta-analysis [36], the authors report that both tics and OCS significantly improved over time $(p<0.01)$. The median time to reach a $40 \%$ improvement of tics was 13 months. However, no significant differences were found between different brain targets $(p>0.05)$. Just recently, Kimura et al. [96] reported about findings from clinical practice and outcome of DBS in TS in Japan. They included 25 patients with refractory TS treated with thalamic CM-Pf DBS. Compared to baseline, tic severity measured by YGTSS-TTS improved by $45.2 \%$ at 1 year, and by $56.6 \%$ at last follow-up 3 years after surgery. Besides reduction of both motor and vocal tics, an improvement of quality of life was observed.

\section{Target selection}

To date it is not clear which target should be selected in TS. The most often used targets are different parts of the thalamus (CM-Pf and CM/Voi) and the postero-ventrolateral and the anteromedial part of the GPi. However, several other targets have been suggested for the management of tics (and comorbidities) in TS including the NA, the ALIC, the globus pallidus externus (GPe), the subthalamic nucleus (STN) and the H Fields of Forel.

According to both the International Deep Brain Stimulation Database and Registry and the two meta-analyses $[35,36]$, no significant differences between targets could be detected. However, both analyses reported that stimulation at the anteromedial GPi resulted in slightly, but nonsignificantly higher improvement rates compared to thalamic 
(centromedian region) DBS-followed by the postero-ventrolateral GPi.

Until today, only three small controlled trials (including 1, 3 and 10 patients, respectively) directly compared two different targets within patients with TS [25, 27, 28]. Houeto et al. [25] $(n=1)$ found that stimulation of either target improved tic severity by $70 \%$, markedly ameliorated coprolalia, and eliminated SIB. Welter et al. [27] $(n=3)$ reported that GPi stimulation resulted in better tic control compared to thalamic DBS, while simultaneous stimulation at both targets did not result in further improvement. However, only thalamic DBS had a positive effect on depressive mood, emotional hypersensitivity, anxiety, and impulsiveness. Another group also reported about increasing incidence of side effects and decreasing efficacy at longterm follow-up in seven patients after thalamic DBS [37]. Moreover, beneficial effects on tics and global functioning of stimulation of unilateral pallidal and nigral thalamic territories have been reported in two patients who presented predominantly with one-sided (contralateral) tics [123]. Finally, a recently published RCT [28] compared efficacy and safety of bilateral thalamus (CM-Voi) versus pvl GPi versus sham stimulation in severe medically refractory GTS. After 36 weeks GPi DBS-but not thalamic DBS resulted in a significant tic reduction compared to baseline, but had no effect on premonitory urges and psychiatric comorbidities. Direct comparisons of both targets to sham stimulation resulted in inconsistent or negative findings. At long-term follow-up on average 6 years after surgery, at group level no significant improvements could be detected, although single patients continuously benefitted from thalamic DBS. Just recently, Servello et al. [124] published results of a retrospective study comparing effects of CM-Voi $(n=41)$ to antero-medial GPi $(n=14)$ stimulation. During an evaluation period of 48 months, both targets were equally effective in reducing tics and beneficial effects persisted over time. With respect to OCD, GPi DBS was superior compared to thalamic stimulation.

Based on available data, it is conceivable that in TS, different targets are comparably effective as is the case in DBS in Parkinson's disease. Whether the GPi and thalamic nuclei form an interconnected common network in terms of a network-modulation involved in symptom improvement of TS is currently under investigation. From preliminary experimental studies a new approach has been suggested by selecting individual targets based on the identification of patterns of connectivity [38, 71, 125].

\section{Adverse events}

When evaluating the value of DBS in TS, type and frequency of AEs has to be considered too. According to the International Deep Brain Stimulation Database and Registry [33], more than one third of patients (35.4\%) experienced AEs. The most frequently reported AEs were stimulation-related (30.8\%) and included dysarthria and paresthesias. Dystonia and dyskinesias were more frequently reported after GPi DBS, while paresthesias and weight gain were more frequently reported after thalamic DBS. The only surgery-related AEs (in 3.8\%) were hemorrhage found in $1.3 \%$ of cases and infections, which occurred with a rate of $2.5 \%$. Only $1.3 \%$ of AEs were device-related. Overall, in TS the average rate of AEs after DBS seems to be similar compared to other patient populations such as dystonia and Parkinson's disease [39, 126, 127].

In contrast to the data from the International Deep Brain Stimulation Database and Registry [33], but in line with other studies [24, 25], Servello et al. [72] reported a higher risk of infections in patients with TS $(18 \%, p<0.001)$ compared to other populations. In a recently published metaanalysis in different populations [127], a mean prevalence rate of surgical site infections of $5.0 \%$ was reported. Infection rates above average were found in epilepsy (9.5\%), dystonia (6.5\%), and TS (5.9\%), while rates were lower in OCD (4.5\%), Parkinson's disease (3.3\%), essential tremor $(2.9 \%)$, and multiple sclerosis (2.4\%). It has been speculated that increased infection rate in TS might be related to complications caused by SIB or alternatively to an underlying immunological dysfunction related to the pathology of TS [36]. However, in a recent study based on the cohort of the Tourette Association of America's International Tourette Syndrome Registry and Database [128], the incidence of lead removal was only $5.6 \%$ and hence lower than previously reported rates in TS [72]. Infections accounted for nearly half of DBS explantations in this cohort. Partly contradictory data might be explained by lack of harmonized methodology to assess AEs such as a unified questionnaire. Further details of the AE profile reported in RCTs and meta-analyses are given in Table 4.

\section{Recommendations from recently published guidelines}

Since the publication of the first ESSTS DBS guidelines in 2011, further guidelines/recommendations specifically for DBS in patients with TS have been published: (i) in 2015 by the Tourette Syndrome Association International Deep Brain Stimulation (DBS) Database and Registry Study Group [129], (ii) in 2019 by an international team of the American Academy of Neurology (AAN) [5], and (iii) in 2021 by an international group of experts [130]. In addition, in 2014 members of different psychiatric and neurosurgical societies published more general consensus guidelines on DBS in psychiatric disorders [131]. Conclusions from the systematic review of the AAN [5] were that (i) the optimal brain target for DBS in TS is still unknown, (ii) DBS of the anteromedial GPi seems to 


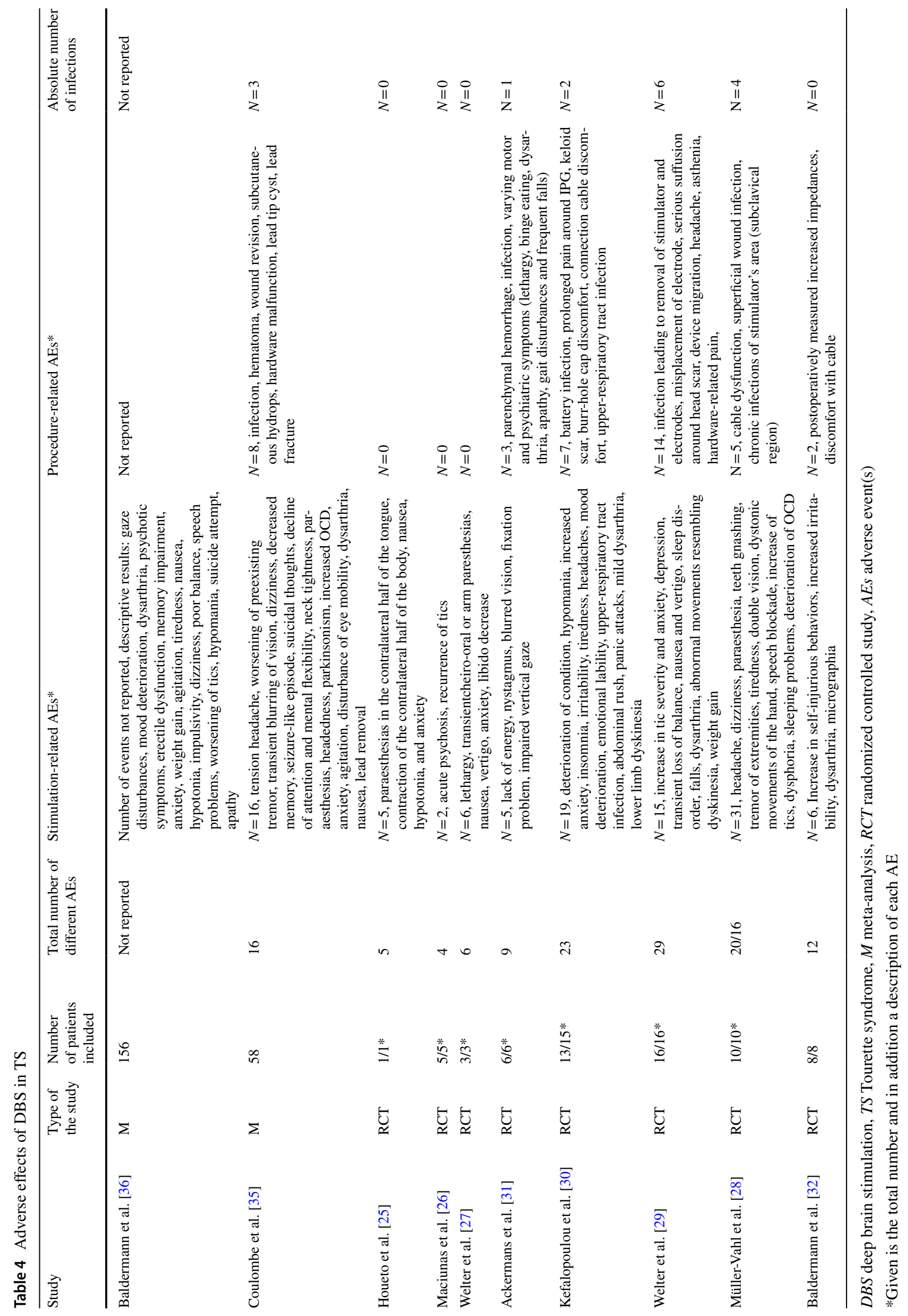




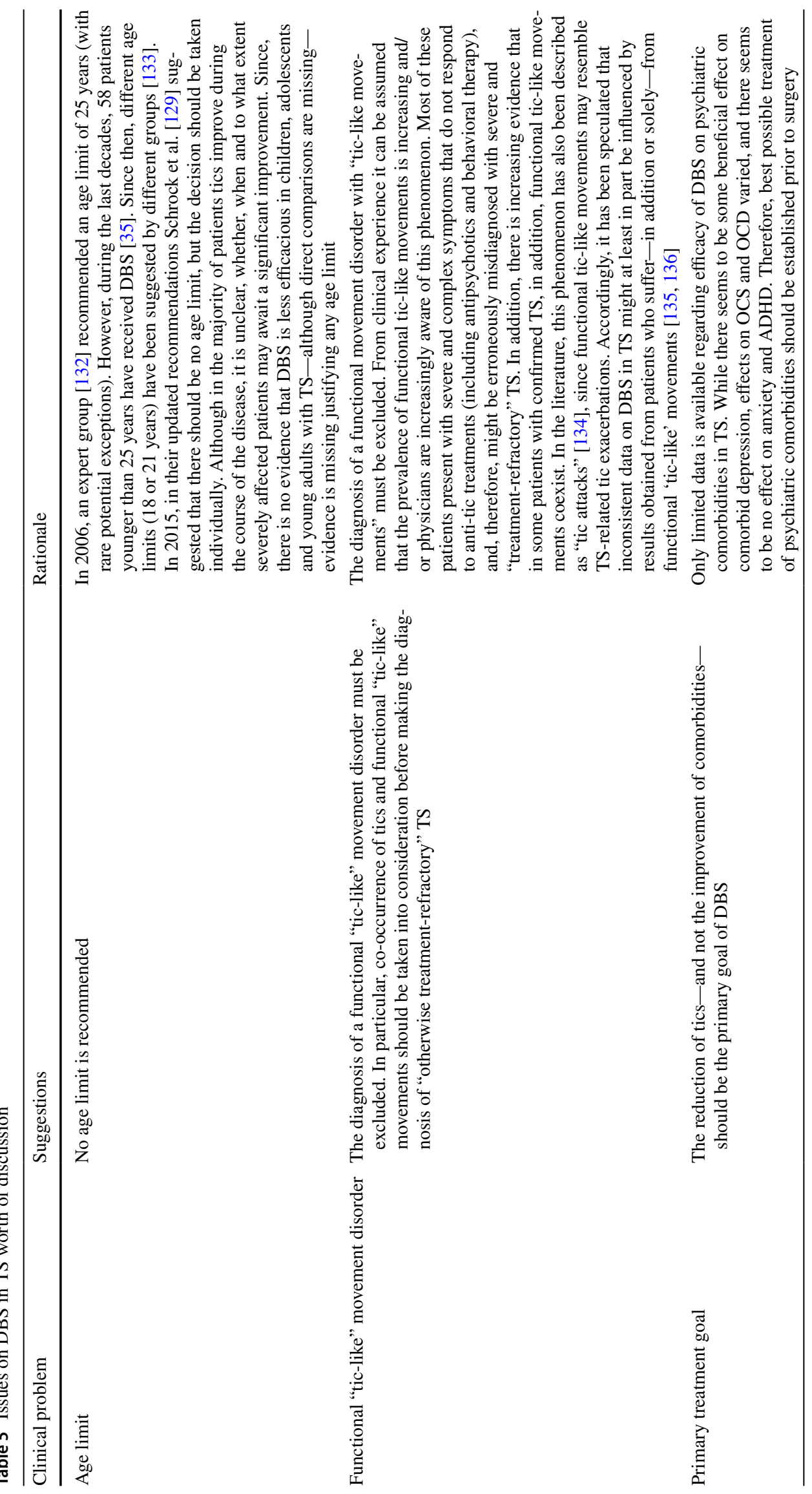




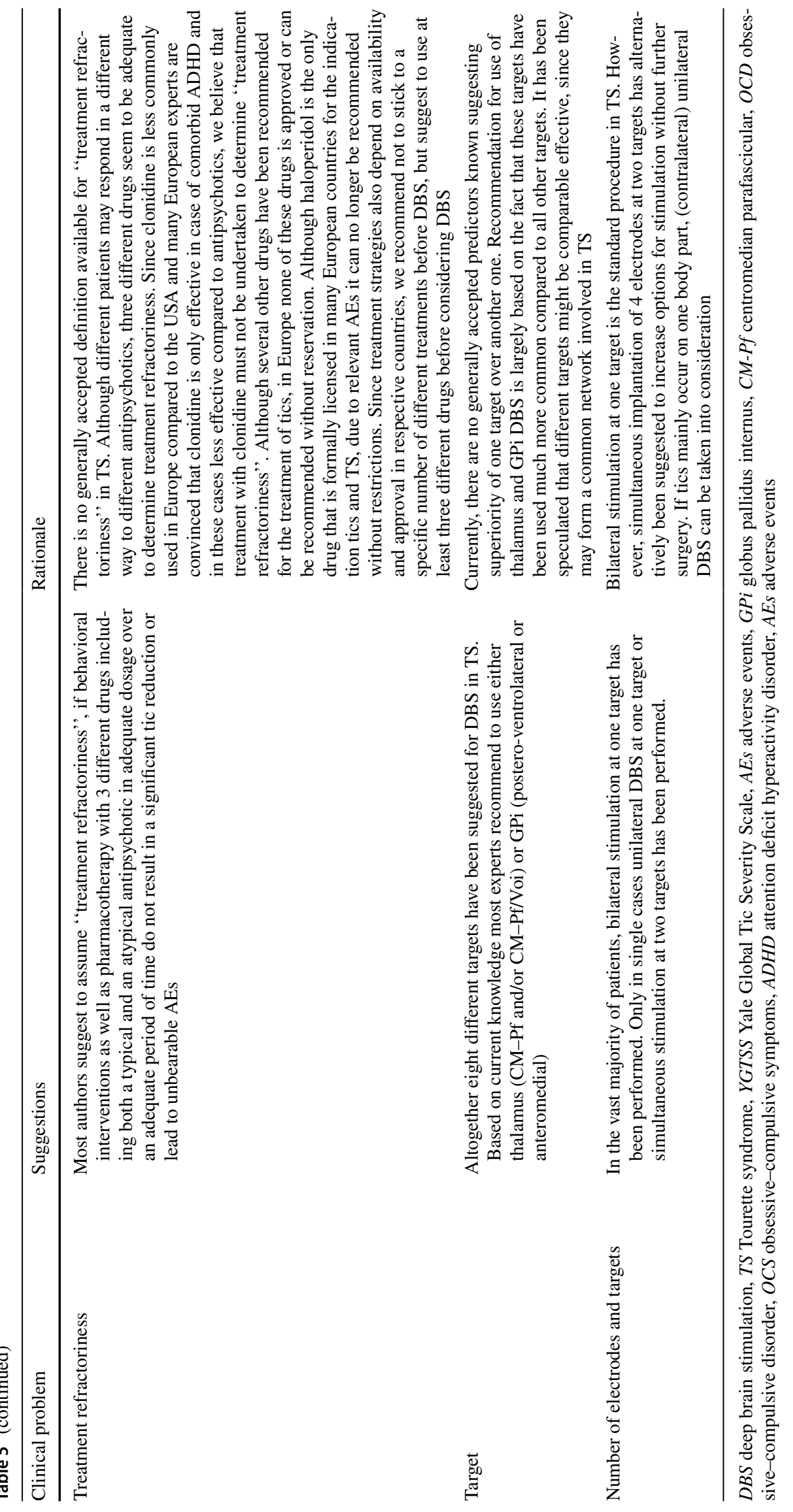


be more effective in reducing tics than sham stimulation, (iii) there is insufficient evidence to confirm efficacy of DBS of thalamic nuclei, and (iv) AEs including infection and removal of hardware, appear more common in patients with TS compared to patients receiving DBS for other indications. However, AAN recommendations [5] - as well as the consensus guidelines published in 2014 [131] — deserve some comment regarding the target selection. In both guidelines, an RCT published by Ackermans et al. [31] describing the results of thalamic DBS in TS was not considered, presumably because of the small sample size of only six patients.

The International Deep Brain Stimulation Database and Registry Study Group [129] gave the following recommendations: (i) patients qualified for the procedure should have a diagnosis of TS with severe motor and vocal tics, which did not respond to behavioral interventions per current expert standards and pharmacological treatments from three pharmacological classes (including alpha-adrenergic agonist, two dopamine antagonists (typical and atypical), and a drug from at least one additional class (e.g., clonazepam, topiramate, tetrabenazine)), (ii) DBS should be offered only to patients in centers that have experience with DBS for this indication and after critical evaluation by a multidisciplinary team, (iii) tics as well as psychiatric comorbidities should be assessed and quantified rigorously pre- and post-operatively, and (iv) functional tics and malingering should be considered in the differential diagnosis.

In 2021, Martino et al. [130] suggested the following principles of DBS in TS: (i) tics should be defined as harmful or malignant for a minimum period of 6 months or should be scored as $\geq 35$ on the YGTSS-TTS for a minimal period of 12 months, (ii) the patient should report at least moderate impairment on the YGTSS impairment score or high impairment on the Gilles de la Tourette Quality of Life Scale (GTSQoL) for a minimal period of 12 months, (iii) patients should be treatment resistant defined as no response to behavioral and/or pharmacological interventions, (iv) co-existing psychiatric conditions should be stable for a minimal period of 6 months prior to surgery and primary impairment of quality of life should be caused by tics, and (v) patients should be older than 18, but in severe cases, patients younger than 18 can be considered.

Since the introduction of DBS in TS, recommendations regarding a minimum age for DBS surgery changed substantially. In 2006, the first guidelines of the Tourette Association of America (TAA) proposed a minimum age of 25 years to ensure that individuals would be past the age of potential spontaneous tic improvement as part of the natural course of the disease, before they were implanted with a surgical device [137]. However, more recent guidelines do not recommend such a rigid age limit any more [5, 129, 130]. Compelling arguments have been made for surgical intervention at younger ages in certain cases of severe TS, given the impact extreme tics can have on the emotional developmental, education, professional development, and relationships. However, some expert groups recommend to involve the local ethics committee in patients under the age of 18 before surgery. Similar suggestions have been made in patients where DBS is considered as "urgent" [129, 130, 138].

In summary, recommendations given in the previously mentioned guidelines are (unsurprisingly) largely overlapping with respect to (i) the involvement of a multidisciplinary team consisting of a psychiatrist or neurologist, neurosurgeon, and neuropsychologist, (ii) confirmation of the diagnosis with severe and/or self-injurious tics that are medication- and behavioral therapy-refractory, and (iii) adequate assessment and treatment of psychiatric comorbidities.

\section{Results of the ESSTS survey}

Our recent online survey among a large number of ESSTS members $(n=59)$ from 17 different European countries addressed specific questions regarding DBS in TS. Although DBS is offered to patients with TS in the particular region (49\%) and center (25\%), respectively, and DBS is accessible in the context of both clinical practice (in $29 \%$ of centers) and of clinical trials (in 15\%), surgery is actually performed only rarely. ESSTS experts estimated to consider DBS in only about $2.5 \%$ (mean, $\pm 5.2 \%$ (SD)) of their patients. On average, only $2.1( \pm 5.7)$ patients per center recommended for DBS underwent surgery in the past 5 years. There is broad consensus among ESSTS experts to consider DBS only in carefully selected, severely affected and otherwise treatment-refractory patients. Only two experts $(3 \%)$ reported to consider DBS "routinely, if behavioral and medical (at least three different drugs) treatment failed to improve tics or caused significant AEs", while $17 \%$ indicated to consider DBS "not at all/never". The majority of ESSTS members $(59 \%)$ reported to consider DBS also in patients under the age of 18 years. Remarkably, patients' interest in DBS seems to be low: according to experts' judgement even in specialized centers on average less than two patients/year $($ mean $=1.8 \pm 2.7)$ ask for DBS.

Although results obtained from the ESSTS survey are affected by several limitations (e.g. small number of participants, no data on how many patients are seen/center relative to those numbers of patients, who were proposed for DBS and who finally underwent surgery in this specific center). However, results from the survey are completely in line with clinical experience in large European TS centers demonstrating that (i) only very few patients ask for DBS, (ii) DBS is recommended only to a very small number of patients, and 
(iii) not all patients decide for DBS although recommended by an expert.

\section{Future developments}

As a new development in conventional DBS, a new approach is suggested for stimulation of patients with various movement disorders including TS using closed-loop adaptive DBS (aDBS) [139]. With this strategy pathological patterns of neuronal activity are identified [140] allowing flexible dynamic adaptation of stimulation parameters fine-tuned to the concurrent therapeutic demand. This approach might help to decrease the incidence of stimulation-related AEs and to preserve the battery for a longer period of time [97, 141]. A requirement for the development of closed loop DBS for TS is the identification of neurophysiological or clinical markers of tic activity. Recently tic-dependent transient rate changes were found in the activity of individual neurons of the anterior (associative/limbic) GPe and GPi of 8 awake patients during DBS electrode implantation surgeries [98]. Finally, use of tractography may be helpful to optimize the technique, to individualize the targeting, and to increase DBS efficacy [99]. Future developments should focus on the application of these novel techniques to identify nonresponders as up to this day it is not clear which parameters predict response to DBS.

\section{Updated recommendations of the ESSTS DBS guidelines group}

Currently no definite conclusions can be drawn on efficacy and safety of DBS in TS and many issues are still a matter of debate (Table 5). Therefore, surgical treatment should still be considered as an experimental therapeutic option for carefully selected patients with otherwise treatment-refractory tics. Noteworthy, RCTs consistently reported fewer positive effects on both tics and psychiatric comorbidities compared to data obtained from uncontrolled studies. This fact should also be taken into consideration when interpreting the results from the available data, meta-analyses, and from the International Deep Brain Stimulation Database and Registry, since the majority of these results are based on open and uncontrolled studies. Furthermore, there are specific DBSrelated methodological difficulties that may hamper RCTs (e.g., very limited study population meeting inclusion criteria, fixed stimulation parameters vs. individually adapted stimulation parameters, inability of adequate blinding, and handling very severely affected subjects who may suffer from SIB in a clinical trial). Finally, DBS RCTs in psychiatric disorders more often fail to show positive results, or show minor results because of the limited time frame, as in the case of (ALIC) DBS RCTs for OCD [142], and depression [143, 144].

The ESSTS DBS guidelines group has the following recommendations for DBS in TS:

(1) A primary diagnosis of TS according to DSM-5 or ICD-10 criteria must be confirmed. These guidelines do not apply to treatment of patients with secondary tics due to other neurological diseases.

(2) The diagnosis of a functional "tic-like" movement disorder must be excluded. In particular, co-occurrence of tics and functional "tic-like" movements should be taken into consideration before making the diagnosis of otherwise treatment-refractory TS [135].

(3) The reduction of tics-and not the improvement of comorbidities - should be the primary goal of DBS in patients with TS [145]. Adequate treatment of psychiatric comorbidities should be established prior to surgery.

(4) DBS should be taken into consideration only in patients with tics that cause significant impairment in patients' quality of life and that are resistant to established conservative treatment strategies including behavioral and pharmacotherapy. Because (i) treatment strategies for tics differ from country to country, (ii) treatment strategies are based on availability of therapies, and (iii) an established definition for "treatment refractoriness" is still lacking, the working group decided not to recommend a specific treatment algorithm before considering DBS. However, before undergoing DBS the patient should be regarded as "otherwise treatment-refractory" in the opinion of a multidisciplinary team which includes refractoriness to both behavioral and pharmacotherapeutical interventions [131].

(5) Both expected treatment efficacy and tolerability must be taken into consideration before the decision on DBS is taken.

(6) We do not recommend a minimum age for operation. However, physicians should be aware that (i) tics often improve spontaneously after puberty and in early adulthood, (ii) the typically spontaneous improvement of tics with increasing age should be thoroughly discussed, (iii) in children - as in adults—abrupt and tremendous deterioration of symptoms might be related to the onset of comorbid functional "tic-like" movements [134] and not as a result of an increase of tics caused by TS, (iv) there is only very limited information on the efficacy of DBS in children with TS, and (v) in children and adolescents involvement of the local ethics committee is recommended.

(7) DBS should be performed in specialized centers by a dedicated multidisciplinary team including a psychi- 
atrist, psychologist and/or neurologist trained in the treatment of patients with TS. This multidisciplinary approach is not only required preoperatively (e.g. for correct diagnosing and assessment of inclusion criteria and judgement on "treatment-refractoriness"), but also during follow-up treatment with regular consultations of both surgical as well as psychiatric or neurological experts.

(8) If possible, DBS should be performed following a specified protocol and within the context of a controlled trial, a cohort study, or registry database, but at least should include systematic pre- and post-DBS assessment of tics, premonitory urges, psychiatric comorbidities (including at least ADHD, OCD, depression, and anxiety), and quality of life.

(9) Physicians should be aware and take into consideration that AEs-and in particular infections-might be more common in patients with TS.

(10) Since it is still unclear, which target is most effective in TS in general and specifically for tic reduction, we do not recommend using a particular target. Based on current data different parts of the thalamus (CM$\mathrm{Pf}$ and $\mathrm{CM} / \mathrm{Voi}$ ) as well as the postero-ventrolateral and the anteromedial part of the GPi seem to generate comparable results. Long-term follow-up of patient characteristics is essential and systematic documentation of long-term outcomes may help disentangle whether specific features of TS are more likely to be responsive to thalamic or pallidal DBS.

Acknowledgements We thank all European TS Advocacy Groups for their collaboration in ESSTS and all patients and families for their participation and support of clinical research.

Funding No funding was received for the work on this manuscript.

Availability of data and materials Not applicable.

Code availability Not applicable.

\section{Declarations}

Conflict of interest JM has received speaker's honoraria from Abbott, Medtronic, Boston Scientific and BrainLab. CG received research grants from the VolkswagenStiftung (Freigeist Fellowship) and the German Parkinson Society and was also supported by the Deutsche Forschungsgemeinschaft (GA2031/1-1 and GA2031/1-2) and Actelion Pharmaceuticals. He also received financial support/ honoraria to speak at meetings by Actelion pharmaceuticals and as ad hoc advisory board for Lundbeck. CD has been awarded travel grants from Medtronic, Boston Scientific and Merz Pharma. AFGL received a research grant from the Michael J Fox Foundation and royalties from Springer media. TF received honoraria for talks sponsored by Boston scientific, Bial and Profile Pharma. He also was funded with grants from NIHR, Innovate UK, Cure Parkinson's trust, Michael J Fox foundation, John Black Charitable Foundation, Van Andel Insti- tute and Defeat MSA. JK has received financial support for Investigator initiated trials from Medtronic $\mathrm{GmbH}$ and grants from the German Research Foundation (KU2665/1-2) and the Marga and Walter Boll Foundation. KMV has received financial or material research support from EU (FP7-HEALTH-2011 No. 278367, FP7-PEOPLE-2012-ITN No. 316978) DFG: GZ MU 1527/3-1 and GZ MU 1527/3-2, BMBF: 01KG1421, National Institute of Mental Health (NIMH), Tourette Gesellschaft Deutschland e.V. Else-Kröner-Fresenius-Stiftung, GW pharmaceuticals, Almirall Hermal GmbH, Abide Therapeutics, and Therapix Biosiences. She has received consultant's honoraria from Abide Therapeutics, Boehringer Ingelheim International $\mathrm{GmbH}$, Bionorica Ethics $\mathrm{GmbH}$, CannaMedical Pharma GmbH, Canopy Grouth, Columbia Care, CTC Communications Corp., Demecan, Eurox Deutschland GmbH, Global Praxis Group Limited, IMC Germany, Lundbeck, Sanity Group, Stadapharm GmbH, Synendos Therapeutics AG, and Tilray. She is an advisory/scientific board member for CannaMedical Pharma $\mathrm{GmbH}$, Bionorica Ethics GmbH, CannaXan GmbH, Canopy Growth, Columbia Care, IMC Germany, Leafly Deutschland GmbH, Sanity Group, Syqe Medical Ltd., Therapix Biosciences Ltd., and Wayland Group. She has received speaker's fees from Aphria Deutschland $\mathrm{GmbH}$, Almirall, Cogitando GmbH, Emalex, Eurox Deutschland $\mathrm{GmbH}$, Ever pharma GmbH, Meinhardt Congress GmbH, PR Berater, Spectrum Therapeutics GmbH, Takeda GmbH, Tilray, Wayland Group. She has received royalties fromDeutsches Ärzteblatt, Der Neurologie und Psychiater, Elsevier, Medizinisch Wissenschaftliche Verlagsgesellschaft Berlin, and Kohlhammer. She served as a guest editor for Frontiers in Neurology on the research topic "The neurobiology and genetics of Gilles de la Tourette syndrome: new avenues through large-scale collaborative projects", is an associate editor for "Cannabis and Cannabinoid Research" and an Editorial Board Member of "Medical Cannabis and Cannabinoids" und "MDPI-Reports" and a Scientific board member for "Zeitschrift für Allgemeinmedizin". AH has received consultancy honoraria from Lundbeck and Noema Pharma. He has received research grants from the Association Française pour le Syndrome Gilles de la Tourette (AFSGT). DC received grant from the EU (TS EUROTRAIN), grant nr. 316978), several grants from ZONMW and MAGW (the Netherlands), from TSA-USA (2008), from Sunovion (DS028 (2019). From Espria fonds, Drenthe, the Netherlands. She has received speakers' fees from ECNP, Psyfar, Benecke, Pfizer. JCB and VVV area funded by the Deutsche Forschungsgemeinschaft, German Research Foundation (Project-ID: 431549029-SFB 1451). All other authors have no conflicts to declare.

Open Access This article is licensed under a Creative Commons Attribution 4.0 International License, which permits use, sharing, adaptation, distribution and reproduction in any medium or format, as long as you give appropriate credit to the original author(s) and the source, provide a link to the Creative Commons licence, and indicate if changes were made. The images or other third party material in this article are included in the article's Creative Commons licence, unless indicated otherwise in a credit line to the material. If material is not included in the article's Creative Commons licence and your intended use is not permitted by statutory regulation or exceeds the permitted use, you will need to obtain permission directly from the copyright holder. To view a copy of this licence, visit http://creativecommons.org/licenses/by/4.0/.

\section{References}

1. Knight T, Steeves T, Day L, Lowerison M, Jette N, Pringsheim $\mathrm{T}$ (2012) Prevalence of tic disorders: a systematic review and meta-analysis. Pediatr Neurol 47(2):77-90

2. Scharf JM, Miller LL, Gauvin CA, Alabiso J, Mathews CA, BenShlomo Y (2015) Population prevalence of Tourette syndrome: a systematic review and meta-analysis. Mov Disord 30(2):221-228 
3. Levine JLS, Szejko N, Bloch MH (2019) Meta-analysis: adulthood prevalence of Tourette syndrome. Prog Neuropsychopharmacol Biol Psychiatry 95:109675

4. Bloch MH, Leckman JF (2009) Clinical course of Tourette syndrome. J Psychosom Res 67(6):497-501

5. Pringsheim T, Okun MS, Müller-Vahl K, Martino D, Jankovic J, Cavanna AE et al (2019) Practice guideline recommendations summary: treatment of tics in people with Tourette syndrome and chronic tic disorders. Neurology 92(19):896-906

6. Pringsheim T, Doja A, Gorman D, McKinlay D, Day L, Billinghurst L et al (2012) Canadian guidelines for the evidence-based treatment of tic disorders: pharmacotherapy. Can J Psychiatry 57(3):133-143

7. Verdellen C, van de Griendt J, Hartmann A, Murphy T (2011) European clinical guidelines for Tourette syndrome and other tic disorders. Part III: behavioural and psychosocial interventions. Eur Child Adolesc Psychiatry 20(4):197-207

8. Roessner V, Plessen KJ, Rothenberger A, Ludolph AG, Rizzo R, Skov L et al (2011) European clinical guidelines for Tourette syndrome and other tic disorders. Part II: pharmacological treatment. Eur Child Adolesc Psychiatry 20(4):173-196

9. Jakobsen KD, Bruhn CH, Pagsberg AK, Fink-Jensen A, Nielsen J (2016) Neurological, metabolic, and psychiatric adverse events in children and adolescents treated with aripiprazole. J Clin Psychopharmacol 36(5):496-499

10. Kious BM, Jimenez-Shahed J, Shprecher DR (2016) Treatmentrefractory Tourette syndrome. Prog Neuropsychopharmacol Biol Psychiatry 70:227-236

11. Macerollo A, Martino D, Cavanna AE, Gulisano M, Hartmann A, Hoekstra PJ et al (2016) Refractoriness to pharmacological treatment for tics: a multicentre European audit. J Neurol Sci 366:136-138

12. Szejko N, Lombroso A, Bloch MH, Landeros-Weisenberger A, Leckman JF (2020) Refractory Gilles de la Tourette syndromemany pieces that define the puzzle. Front Neurol 11:589511

13. Sambrani T, Jakubovski E, Müller-Vahl KR (2016) New insights into clinical characteristics of Gilles de la Tourette syndrome: findings in 1032 patients from a single German center. Front Neurosci 10:415

14. Jalenques I, Galland F, Malet L, Morand D, Legrand G, Auclair C et al (2012) Quality of life in adults with Gilles de la Tourette syndrome. BMC Psychiatry 12(1):109

15. Müller-Vahl K, Dodel I, Müller N, Münchau A, Reese JP, Balzer-Geldsetzer M et al (2010) Health-related quality of life in patients with Gilles de la Tourette's syndrome. Mov Disord 25(3):309-314

16. Dell'Osso B, Marazziti D, Albert U, Pallanti S, Gambini O, Tundo A et al (2017) Parsing the phenotype of obsessive-compulsive tic disorder (OCTD): a multidisciplinary consensus. Int J Psychiatry Clin Pract 21(2):156-159

17. Porta M, Cavanna AE, Zekaj E, D’Adda F, Servello D (2013) Selection of patients with Tourette syndrome for deep brain stimulation surgery. Behav Neurol 27(1):125-131

18. Müller-Vahl KR, Cath DC, Cavanna AE, Dehning S, Porta M, Robertson MM et al (2011) European clinical guidelines for Tourette syndrome and other tic disorders. Part IV: deep brain stimulation. Eur Child Adolesc Psychiatry 20(4):209-217

19. Kushner H (2000) A Cursing Brain? The Histories of Tourette Syndrome. Bibliovault OAI Repository, the University of Chicago Press

20. Hassler R, Dieckmann G (1970) Stereotaxic treatment of tics and inarticulate cries or coprolalia considered as motor obsessional phenomena in Gilles de la Tourette's disease. Rev Neurol (Paris) 123(2):89-100

21. Rickards H, Wood C, Cavanna AE (2008) Hassler and Dieckmann's seminal paper on stereotactic thalamotomy for Gilles de la Tourette syndrome: translation and critical reappraisal. Mov Disord 23(14):1966-1972

22. Babel TB, Warnke PC, Ostertag CB (2001) Immediate and long term outcome after infrathalamic and thalamic lesioning for intractable Tourette's syndrome. J Neurol Neurosurg Psychiatry 70(5):666-671

23. Vandewalle V, van der Linden C, Groenewegen HJ, Caemaert J (1999) Stereotactic treatment of Gilles de la Tourette syndrome by high frequency stimulation of thalamus. Lancet 353(9154):724

24. Müller-Vahl KR, Szejko N, Verdellen C, Roessner V, Hoekstra PJ, Hartmann A et al (2021) European clinical guidelines for Tourette syndrome and other tic disorders: summary statement. Eur Child Adolesc Psychiatry. https://doi.org/10.1007/ s00787-021-01832-4

25. Houeto JL, Karachi C, Mallet L, Pillon B, Yelnik J, Mesnage V et al (2005) Tourette's syndrome and deep brain stimulation. J Neurol Neurosurg Psychiatry 76(7):992-995

26. Maciunas RJ, Maddux BN, Riley DE, Whitney CM, Schoenberg MR, Ogrocki PJ et al (2007) Prospective randomized doubleblind trial of bilateral thalamic deep brain stimulation in adults with Tourette syndrome. J Neurosurg 107(5):1004-1014

27. Welter ML, Mallet L, Houeto JL, Karachi C, Czernecki V, Cornu P et al (2008) Internal pallidal and thalamic stimulation in patients with Tourette syndrome. Arch Neurol 65(7):952-957

28. Müller-Vahl KR, Szejko N, Saryyeva A, Schrader C, Krueger D, Horn A et al (2021) Randomized double-blind sham-controlled trial of thalamic versus GPi stimulation in patients with severe medically refractory Gilles de la Tourette syndrome. Brain Stimul 14(3):662-675

29. Welter ML, Houeto JL, Thobois S, Bataille B, Guenot M, Worbe $Y$ et al (2017) Anterior pallidal deep brain stimulation for Tourette's syndrome: a randomised, double-blind, controlled trial. Lancet Neurol 16(8):610-619

30. Kefalopoulou Z, Zrinzo L, Jahanshahi M, Candelario J, Milabo C, Beigi M et al (2015) Bilateral globus pallidus stimulation for severe Tourette's syndrome: a double-blind, randomised crossover trial. Lancet Neurol 14(6):595-605

31. Ackermans L, Duits A, van der Linden C, Tijssen M, Schruers $\mathrm{K}$, Temel Y et al (2011) Double-blind clinical trial of thalamic stimulation in patients with Tourette syndrome. Brain $134(\mathrm{Pt}$ 3):832-844

32. Baldermann JC, Kuhn J, Schüller T, Kohl S, Andrade P, Schleyken S et al (2021) Thalamic deep brain stimulation for Tourette syndrome: a naturalistic trial with brief randomized, double-blinded sham-controlled periods. Brain Stimul 14(5):1059-1067

33. Martinez-Ramirez D, Jimenez-Shahed J, Leckman JF, Porta M, Servello D, Meng FG et al (2018) Efficacy and safety of deep brain stimulation in Tourette syndrome: the international Tourette syndrome deep brain stimulation public database and registry. JAMA Neurol 75(3):353-359

34. Johnson KA, Fletcher PT, Servello D, Bona A, Porta M, Ostrem JL et al (2019) Image-based analysis and long-term clinical outcomes of deep brain stimulation for Tourette syndrome: a multisite study. J Neurol Neurosurg Psychiatry 90(10):1078-1090

35. Coulombe MA, Elkaim LM, Alotaibi NM, Gorman DA, Weil AG, Fallah A et al (2018) Deep brain stimulation for Gilles de la Tourette syndrome in children and youth: a meta-analysis with individual participant data. J Neurosurg Pediatr 23(2):236-246

36. Baldermann JC, Schüller T, Huys D, Becker I, Timmermann L, Jessen F et al (2016) Deep brain stimulation for Tourettesyndrome: a systematic review and meta-analysis. Brain Stimul 9(2):296-304

37. Smeets A, Duits AA, Leentjens AFG, Schruers K, van KranenMastenbroek V, Visser-Vandewalle V et al (2018) Thalamic deep 
brain stimulation for refractory Tourette syndrome: clinical evidence for increasing disbalance of therapeutic effects and side effects at long-term follow-up. Neuromodulation 21(2):197-202

38. Kakusa B, Saluja S, Barbosa DAN, Cartmell S, Espil FM, Williams NR et al (2021) Evidence for the role of the dorsal ventral lateral posterior thalamic nucleus connectivity in deep brain stimulation for Gilles de la Tourette syndrome. J Psychiatr Res 132:60-64

39. Buhmann C, Huckhagel T, Engel K, Gulberti A, Hidding U, Poetter-Nerger $\mathrm{M}$ et al (2017) Adverse events in deep brain stimulation: A retrospective long-term analysis of neurological, psychiatric and other occurrences. PLoS ONE 12(7):e0178984

40. Ackermans L, Temel Y, Bauer NJ, Visser-Vandewalle V (2007) Vertical gaze palsy after thalamic stimulation for Tourette syndrome: case report. Neurosurgery 61(5):E1100 (discussion E)

41. Neuner I, Podoll K, Lenartz D, Sturm V, Schneider F (2009) Deep brain stimulation in the nucleus accumbens for intractable Tourette's syndrome: follow-up report of 36 months. Biol Psychiatry 65(4):e5-6

42. Shahed J, Poysky J, Kenney C, Simpson R, Jankovic J (2007) GPi deep brain stimulation for Tourette syndrome improves tics and psychiatric comorbidities. Neurology 68(2):159-160

43. Shields DC, Cheng ML, Flaherty AW, Gale JT, Eskandar EN (2008) Microelectrode-guided deep brain stimulation for Tourette syndrome: within-subject comparison of different stimulation sites. Stereotact Funct Neurosurg 86(2):87-91

44. Zabek M, Sobstyl M, Koziara H, Dzierzecki S (2008) Deep brain stimulation of the right nucleus accumbens in a patient with Tourette syndrome. Case report. Neurol Neurochir Pol 42(6):554-559

45. Dwarakanath S, Hegde A, Ketan J, Chandrajit P, Yadav R, Keshav K et al (2017) "I swear, I can't stop it!"-a case of severe Tourette's syndrome treated with deep brain stimulation of anteromedial globus pallidus interna. Neurol India 65(1):99-102

46. Servello D, Sassi M, Brambilla A, Porta M, Haq I, Foote KD et al (2009) De novo and rescue DBS leads for refractory Tourette syndrome patients with severe comorbid OCD: a multiple case report. J Neurol 256(9):1533-1539

47. Zhang C, Li H, Pan Y, Jin H, Sun B, Wu Y et al (2019) Pallidal neurostimulation and capsulotomy for malignant Tourette's syndrome. Mov Disord Clin Pract 6(5):393-395

48. Kakusa B, Saluja S, Tate WJ, Espil FM, Halpern CH, Williams NR (2019) Robust clinical benefit of multi-target deep brain stimulation for treatment of Gilles de la Tourette syndrome and its comorbidities. Brain Stimul 12(3):816-818

49. Burdick A, Foote KD, Goodman W, Ward HE, Ricciuti N, Murphy T et al (2010) Lack of benefit of accumbens/capsular deep brain stimulation in a patient with both tics and obsessive-compulsive disorder. Neurocase 16(4):321-330

50. Marano M, Migliore S, Squitieri F, Insola A, Scarnati E, Mazzone P (2019) CM-Pf deep brain stimulation and the long term management of motor and psychiatric symptoms in a case of Tourette syndrome. J Clin Neurosci 62:269-272

51. Kilincaslan A, Aydin S, Kok BE, Akcakaya H, Yapici Z (2017) Pallidal stimulation in an 11-year-old boy with treatmentresistant Tourette syndrome. J Child Adolesc Psychopharmacol 27(7):673-674

52. Picillo M, Rohani M, Lozano AM, Fasano A (2017) Two indications, one target: Concomitant epilepsy and Tourettism treated with Centromedian/parafascicular thalamic stimulation. Brain Stimul 10(3):711-713

53. Testini P, Min HK, Bashir A, Lee KH (2016) deep brain stimulation for Tourette's syndrome: the case for targeting the thalamic centromedian-parafascicular complex. Front Neurol 7:193

54. Kuhn J, Lenartz D, Huff W, Mai JK, Koulousakis A, Maarouf $\mathrm{M}$ et al (2008) Transient manic-like episode following bilateral deep brain stimulation of the nucleus accumbens and the internal capsule in a patient with Tourette syndrome. Neuromodulation 11(2):128-131

55. Cury RG, Lopez WO, Dos Santos Ghilardi MG, Barbosa DC, Barbosa ER, Teixeira MJ et al (2016) Parallel improvement in anxiety and tics after DBS for medically intractable Tourette syndrome: a long-term follow-up. Clin Neurol Neurosurg 144:33-35

56. Zekaj E, Saleh C, Porta M, Servello D (2015) Temporary deep brain stimulation in Gilles de la Tourette syndrome: a feasible approach? Surg Neurol Int 6:122

57. Dong S, Zhang X, Li J, Li Y (2014) The benefits of low-frequency pallidal deep brain stimulation in a patient with Tourette syndrome. Parkinsonism Relat Disord 20(12):1438-1439

58. Patel N, Jimenez-Shahed J (2014) Simultaneous improvement of tics and parkinsonism after pallidal DBS. Parkinsonism Relat Disord 20(9):1022-1023

59. Dehning S, Mehrkens JH, Müller N, Bötzel K (2008) Therapy-refractory Tourette syndrome: beneficial outcome with globus pallidus internus deep brain stimulation. Mov Disord 23(9):1300-1302

60. Huasen B, McCreary R, Evans J, Potter G, Silverdale M (2014) Cervical myelopathy secondary to Tourette's syndrome managed by urgent deep brain stimulation. Mov Disord 29(4):452-453

61. Piedimonte F, Andreani JC, Piedimonte L, Graff P, Bacaro V, Micheli F et al (2013) Behavioral and motor improvement after deep brain stimulation of the globus pallidus externus in a case of Tourette's syndrome. Neuromodulation 16(1):55-58 (discussion 8)

62. Idris Z, Ghani AR, Mar W, Bhaskar S, Wan Hassan WN, Tharakan J et al (2010) Intracerebral haematomas after deep brain stimulation surgery in a patient with Tourette syndrome and low factor XIIIA activity. J Clin Neurosci 17(10):1343-1344

63. Diederich NJ, Kalteis K, Stamenkovic M, Pieri V, Alesch F (2005) Efficient internal pallidal stimulation in Gilles de la Tourette syndrome: a case report. Mov Disord 20(11):1496-1499

64. Dueck A, Wolters A, Wunsch K, Bohne-Suraj S, Mueller JU, Haessler F et al (2009) Deep brain stimulation of globus pallidus internus in a 16-year-old boy with severe Tourette syndrome and mental retardation. Neuropediatrics 40(5):239-242

65. Flaherty AW, Williams ZM, Amirnovin R, Kasper E, Rauch SL, Cosgrove GR et al (2005) Deep brain stimulation of the anterior internal capsule for the treatment of Tourette syndrome: technical case report. Neurosurgery 57(4 Suppl):E403 (discussion E)

66. Gallagher CL, Garell PC, Montgomery EB Jr (2006) Hemi tics and deep brain stimulation. Neurology 66(3):E12

67. Kuhn J, Lenartz D, Mai JK, Huff W, Lee SH, Koulousakis A et al (2007) Deep brain stimulation of the nucleus accumbens and the internal capsule in therapeutically refractory Tourette-syndrome. J Neurol 254(7):963-965

68. Martinez-Torres I, Hariz MI, Zrinzo L, Foltynie T, Limousin P (2009) Improvement of tics after subthalamic nucleus deep brain stimulation. Neurology 72(20):1787-1789

69. Cagle JN, Deeb W, Eisinger RS, Molina R, Opri E, Holland MT et al (2020) Lead repositioning guided by both physiology and atlas based targeting in Tourette deep brain stimulation. Tremor Other Hyperkinet Mov (N Y) 10:18

70. Duarte-Batista P, Coelho M, Quintas S, Levy P, Castro Caldas A, Gonçalves-Ferreira A et al (2020) Anterior limb of internal capsule and bed nucleus of stria terminalis stimulation for Gilles de la Tourette syndrome with obsessive-compulsive disorder in adolescence: a case of success. Stereotact Funct Neurosurg 98(2):95-103

71. Johnson KA, Duffley G, Foltynie T, Hariz M, Zrinzo L, Joyce EM et al (2020) Basal ganglia pathways associated with therapeutic pallidal deep brain stimulation for Tourette syndrome. 
Biol Psychiatry Cogn Neurosci Neuroimaging. https://doi.org/ 10.1016/j.bpsc.2020.11.005

72. Servello D, Sassi M, Gaeta M, Ricci C, Porta M (2011) Tourette syndrome (TS) bears a higher rate of inflammatory complications at the implanted hardware in deep brain stimulation (DBS). Acta Neurochir (Wien) 153(3):629-632

73. Xu W, Zhang X, Wang Y, Gong H, Wu Y, Sun B et al (2021) Sustained relief after pallidal stimulation interruption in Tourette's syndrome treated with simultaneous capsulotomy. Stereotact Funct Neurosurg 99(2):140-149

74. Doshi PK, Ramdasi R, Thorve S (2018) Deep brain stimulation of anteromedial globus pallidus internus for severe Tourette syndrome. Indian J Psychiatry 60(1):138-140

75. Servello D, Zekaj E, Saleh C, Lange N, Porta M (2016) Deep brain stimulation in Gilles de la Tourette syndrome: what does the future hold? A cohort of 48 patients. Neurosurgery 78(1):91-100

76. Motlagh MG, Smith ME, Landeros-Weisenberger A, Kobets AJ, King RA, Miravite J et al (2013) Lessons learned from openlabel deep brain stimulation for Tourette syndrome: eight cases over 7 years. Tremor Other Hyperkinet Mov (N Y) 3:3

77. Testini P, Zhao CZ, Stead M, Duffy PS, Klassen BT, Lee KH (2016) Centromedian-parafascicular complex deep brain stimulation for Tourette syndrome: a retrospective study. Mayo Clin Proc 91(2):218-225

78. Savica R, Stead M, Mack KJ, Lee KH, Klassen BT (2012) Deep brain stimulation in Tourette syndrome: a description of 3 patients with excellent outcome. Mayo Clin Proc 87(1):59-62

79. Viswanathan A, Jimenez-Shahed J, Baizabal Carvallo JF, Jankovic J (2012) Deep brain stimulation for Tourette syndrome: target selection. Stereotact Funct Neurosurg 90(4):213-224

80. Kano Y, Matsuda N, Nonaka M, Fujio M, Kono T, Kaido T (2018) Sensory phenomena and obsessive-compulsive symptoms in Tourette syndrome following deep brain stimulation: two case reports. J Clin Neurosci 56:199-201

81. Azimi A, Parvaresh M, Shahidi G, Habibi A, Rohani S, Safdarian M et al (2018) Anteromedial GPi deep brain stimulation in Tourette syndrome: the first case series from Iran. Clin Neurol Neurosurg 172:116-119

82. Canaz H, Karalok I, Topcular B, Agaoglu M, Yapici Z, Aydin S (2018) DBS in pediatric patients: institutional experience. Childs Nerv Syst 34(9):1771-1776

83. Neudorfer C, El Majdoub F, Hunsche S, Richter K, Sturm V, Maarouf M (2017) Deep brain stimulation of the H Fields of forel alleviates tics in Tourette syndrome. Front Hum Neurosci 11:308

84. Ackermans L, Temel Y, Cath D, van der Linden C, Bruggeman R, Kleijer M et al (2006) Deep brain stimulation in Tourette's syndrome: two targets? Mov Disord 21(5):709-713

85. Dowd RS, Pourfar M, Mogilner AY (2018) Deep brain stimulation for Tourette syndrome: a single-center series. J Neurosurg 128(2):596-604

86. Zhang J-G, Ge Y, Stead M, Zhang K, Yan S-S, Hu W et al (2014) Long-term outcome of globus pallidus internus deep brain stimulation in patients with Tourette syndrome. Mayo Clin Proc 89(11):1506-1514

87. Bour LJ, Ackermans L, Foncke EM, Cath D, van der Linden C, Visser Vandewalle V et al (2015) Tic related local field potentials in the thalamus and the effect of deep brain stimulation in Tourette syndrome: report of three cases. Clin Neurophysiol 126(8):1578-1588

88. Servello D, Sassi M, Brambilla A, Defendi S, Porta M (2010) Long-term, post-deep brain stimulation management of a series of 36 patients affected with refractory Gilles de la Tourette syndrome. Neuromodulation 13(3):187-194

89. Hauseux PA, Cyprien F, Cif L, Gonzalez V, Boulenger JP, Coubes P et al (2017) Long-term follow-up of pallidal Deep
Brain Stimulation in teenagers with refractory Tourette syndrome and comorbid psychiatric disorders: about three cases. Eur J Paediatr Neurol 21(1):214-217

90. Zhang XH, Li JY, Zhang YQ, Li YJ (2016) Deep brain stimulation of the globus pallidus internus in patients with intractable Tourette syndrome: a 1-year follow-up study. Chin Med J (Engl) 129(9):1022-1027

91. Servello D, Porta M, Sassi M, Brambilla A, Robertson MM (2008) Deep brain stimulation in 18 patients with severe Gilles de la Tourette syndrome refractory to treatment: the surgery and stimulation. J Neurol Neurosurg Psychiatry 79(2):136-142

92. Martínez-Fernández R, Zrinzo L, Aviles-Olmos I, Hariz M, Martinez-Torres I, Joyce E et al (2011) Deep brain stimulation for Gilles de la Tourette syndrome: a case series targeting subregions of the globus pallidus internus. Mov Disord 26(10):1922-1930

93. Sachdev PS, Mohan A, Cannon E, Crawford JD, Silberstein P, Cook R et al (2014) Deep brain stimulation of the antero-medial globus pallidus interna for Tourette syndrome. PLoS ONE 9(8):e104926

94. Marceglia S, Prenassi M, Galbiati TF, Porta M, Zekaj E, Priori A et al (2021) Thalamic local field potentials are related to longterm DBS effects in Tourette syndrome. Front Neurol 12:578324

95. Welter ML, Houeto JL, Worbe Y, Diallo MH, Hartmann A, Tezenas du Montcel S et al (2019) Long-term effects of anterior pallidal deep brain stimulation for tourette's syndrome. Mov Disord 34(4):586-588

96. Kimura Y, Iijima K, Takayama Y, Yokosako S, Kaneko Y, Omori $M$ et al (2021) Deep brain stimulation for refractory Tourette syndrome: electrode position and clinical outcome. Neurol Med Chir (Tokyo) 61(1):33-39

97. Marceglia S, Rosa M, Servello D, Porta M, Barbieri S, Moro E et al (2017) Adaptive deep brain stimulation (aDBS) for Tourette syndrome. Brain Sci 8(1):4

98. Israelashvili M, Smeets A, Bronfeld M, Zeef DH, Leentjens AFG, van Kranen-Mastenbroek V et al (2017) Tonic and phasic changes in anteromedial globus pallidus activity in Tourette syndrome. Mov Disord 32(7):1091-1096

99. Andrade P, Heiden P, Hoevels M, Schlamann M, Baldermann JC, Huys D et al (2020) Modulation of fibers to motor cortex during thalamic DBS in Tourette patients correlates with tic reduction. Brain Sci 10(5):302

100. Morreale F, Kefalopoulou Z, Zrinzo L, Limousin P, Joyce E, Foltynie $T$ et al (2021) Inhibitory control on a stop signal task in Tourette syndrome before and after deep brain stimulation of the internal segment of the globus pallidus. Brain Sci 11(4):461

101. Schleyken S, Baldermann J, Huys D, Franklin J, Visser-Vandewalle V, Kuhn J et al (2020) Deep brain stimulation and sensorimotor gating in tourette syndrome and obsessive-compulsive disorder. J Psychiatr Res 129:272-280

102. Akbarian-Tefaghi L, Akram H, Johansson J, Zrinzo L, Kefalopoulou Z, Limousin P et al (2017) Refining the deep brain stimulation target within the limbic globus pallidus internus for Tourette syndrome. Stereotact Funct Neurosurg 95(4):251-258

103. Haense C, Müller-Vahl KR, Wilke F, Schrader C, Capelle HH, Geworski L et al (2016) Effect of deep brain stimulation on regional cerebral blood flow in patients with medically refractory Tourette syndrome. Front Psychiatry 7:118

104. Shute JB, Okun MS, Opri E, Molina R, Rossi PJ, MartinezRamirez D et al (2016) Thalamocortical network activity enables chronic tic detection in humans with Tourette syndrome. Neuroimage Clin 12:165-172

105. Rossi PJ, Opri E, Shute JB, Molina R, Bowers D, Ward H et al (2016) Scheduled, intermittent stimulation of the thalamus reduces tics in Tourette syndrome. Parkinsonism Relat Disord $29: 35-41$ 
106. Albert JM, Maddux BN, Riley DE, Maciunas RJ (2009) Modeling video tic counts in a crossover trial of deep brain stimulation for Tourette syndrome. Contemp Clin Trials 30(2):141-149

107. Kaido T, Otsuki T, Kaneko Y, Takahashi A, Omori M, Okamoto $\mathrm{T}$ (2011) Deep brain stimulation for Tourette syndrome: a prospective pilot study in Japan. Neuromodulation 14(2):123-128 (discussion 9)

108. Loza CA, Shute JB, Principe JC, Okun MS, Gunduz A (2017) A marked point process approach for identifying neural correlates of tics in Tourette Syndrome. Annu Int Conf IEEE Eng Med Biol Soc 2017:4375-4378

109. Molina R, Okun MS, Shute JB, Opri E, Rossi PJ, MartinezRamirez D et al (2018) Report of a patient undergoing chronic responsive deep brain stimulation for Tourette syndrome: proof of concept. J Neurosurg 129(2):308-314

110. Wårdell K, Kefalopoulou Z, Diczfalusy E, Andersson M, Åström M, Limousin P et al (2015) Deep brain stimulation of the pallidum internum for Gilles de la Tourette syndrome: a patientspecific model-based simulation study of the electric field. Neuromodulation 18(2):90-96

111. Schoenberg MR, Maddux BN, Riley DE, Whitney CM, Ogrocki PK, Gould D et al (2015) Five-months-postoperative neuropsychological outcome from a pilot prospective randomized clinical trial of thalamic deep brain stimulation for Tourette syndrome. Neuromodulation 18(2):97-104

112. Alam M, Schwabe K, Lütjens G, Capelle HH, Manu M, von Wrangel C et al (2015) Comparative characterization of single cell activity in the globus pallidus internus of patients with dystonia or Tourette syndrome. J Neural Transm (Vienna) 122(5):687-699

113. Huys D, Bartsch C, Koester P, Lenartz D, Maarouf M, Daumann $\mathrm{J}$ et al (2016) Motor improvement and emotional stabilization in patients with Tourette syndrome after deep brain stimulation of the ventral anterior and ventrolateral motor part of the thalamus. Biol Psychiatry 79(5):392-401

114. Dehning S, Leitner B, Schennach R, Müller N, Bötzel K, Obermeier $\mathrm{M}$ et al (2014) Functional outcome and quality of life in Tourette's syndrome after deep brain stimulation of the posteroventrolateral globus pallidus internus: long-term follow-up. World J Biol Psychiatry 15(1):66-75

115. Maling N, Hashemiyoon R, Foote KD, Okun MS, Sanchez JC (2012) Increased thalamic gamma band activity correlates with symptom relief following deep brain stimulation in humans with Tourette's syndrome. PLoS ONE 7(9):e44215

116. Porta M, Servello D, Zanaboni C, Anasetti F, Menghetti C, Sassi $M$ et al (2012) Deep brain stimulation for treatment of refractory Tourette syndrome: long-term follow-up. Acta Neurochir (Wien) 154(11):2029-2041

117. Vissani M, Cordella R, Micera S, Eleopra R, Romito LM, Mazzoni A (2019) Spatio-temporal structure of single neuron subthalamic activity identifies DBS target for anesthetized Tourette syndrome patients. J Neural Eng 16(6):066011

118. Brito M, Teixeira MJ, Mendes MM, França C, Iglesio R, Barbosa ER et al (2019) Exploring the clinical outcomes after deep brain stimulation in Tourette syndrome. J Neurol Sci 402:48-51

119. Zhang C, Deng Z, Pan Y, Zhang J, Zeljic K, Jin H et al (2019) Pallidal deep brain stimulation combined with capsulotomy for Tourette's syndrome with psychiatric comorbidity. J Neurosurg 131(6):1788-1796

120. Neumann WJ, Huebl J, Brücke C, Lofredi R, Horn A, Saryyeva A et al (2018) Pallidal and thalamic neural oscillatory patterns in Tourette's syndrome. Ann Neurol 84(4):505-514

121. Jo HJ, McCairn KW, Gibson WS, Testini P, Zhao CZ, Gorny KR et al (2018) Global network modulation during thalamic stimulation for Tourette syndrome. Neuroimage Clin 18:502-509
122. Giorni A, Windels F, Stratton PG, Cook R, Silberstein P, Coyne $T$ et al (2017) Single-unit activity of the anterior Globus pallidus internus in Tourette patients and posterior Globus pallidus internus in dystonic patients. Clin Neurophysiol 128(12):2510-2518

123. Kuhn J, Bartsch C, Lenartz D, Huys D, Daumann J, Woopen C et al (2011) Clinical effectiveness of unilateral deep brain stimulation in Tourette syndrome. Transl Psychiatry 1(11):e52

124. Servello D, Galbiati TF, Balestrino R, Iess G, Zekaj E, Michele $S$ et al (2020) Deep brain stimulation for Gilles de la Tourette syndrome: toward limbic targets. Brain Sci 10(5):301

125. Heiden P, Hoevels M, Bayram D, Baldermann JC, Schüller T, Huys D et al (2021) Connectivity patterns of deep brain stimulation targets in patients with Gilles de la Tourette syndrome. Brain Sci 11(1):87

126. Koy A, Weinsheimer M, Pauls KA, Kühn AA, Krause P, Huebl J et al (2017) German registry of paediatric deep brain stimulation in patients with childhood-onset dystonia (GEPESTIM). Eur J Paediatr Neurol 21(1):136-146

127. Kantzanou M, Korfias S, Panourias I, Sakas DE, Karalexi MA (2021) Deep brain stimulation-related surgical site infections: a systematic review and meta-analysis. Neuromodulation 24(2):197-211

128. Deeb W, Leentjens AFG, Mogilner AY, Servello D, Meng F, Zhang J et al (2020) Deep brain stimulation lead removal in Tourette syndrome. Parkinsonism Relat Disord 77:89-93

129. Schrock LE, Mink JW, Woods DW, Porta M, Servello D, VisserVandewalle V et al (2015) Tourette syndrome deep brain stimulation: a review and updated recommendations. Mov Disord 30(4):448-471

130. Martino D, Deeb W, Jimenez-Shahed J, Malaty I, Pringsheim TM, Fasano A et al (2021) The 5 pillars in Tourette syndrome deep brain stimulation patient selection: present and future. Neurology 96(14):664-676

131. Nuttin B, Wu H, Mayberg H, Hariz M, Gabriëls L, Galert T et al (2014) Consensus on guidelines for stereotactic neurosurgery for psychiatric disorders. J Neurol Neurosurg Psychiatry 85(9):1003-1008

132. Riley DE, Whitney CM, Maddux BN, Schoenberg MS, Maciunas RJ (2007) Patient selection and assessment recommendations for deep brain stimulation in Tourette syndrome. Mov Disord 22(9):1366 (author reply 7-8)

133. Xu W, Zhang C, Deeb W, Patel B, Wu Y, Voon V et al (2020) Deep brain stimulation for Tourette's syndrome. Transl Neurodegener 9:4

134. Robinson S, Hedderly T (2016) Novel psychological formulation and treatment of "tic attacks" in Tourette syndrome. Front Pediatr $4: 46$

135. Ganos C, Martino D, Espay AJ, Lang AE, Bhatia KP, Edwards MJ (2019) Tics and functional tic-like movements: can we tell them apart? Neurology 93(17):750-758

136. Muller-Vahl KR (2019) Deep brain stimulation in Tourette syndrome: the known and the unknown. J Neurol Neurosurg Psychiatry 90(10): 1076-1077

137. Mink JW, Walkup J, Frey KA, Como P, Cath D, Delong MR et al (2006) Patient selection and assessment recommendations for deep brain stimulation in Tourette syndrome. Mov Disord 21(11):1831-1838

138. Smeets A, Duits AA, Horstkötter D, Verdellen C, de Wert G, Temel Y et al (2018) Ethics of deep brain stimulation in adolescent patients with refractory Tourette syndrome: a systematic review and two case discussions. Neuroethics 11(2):143-155

139. Neumann WJ, Turner RS, Blankertz B, Mitchell T, Kühn AA, Richardson RM (2019) Toward electrophysiology-based intelligent adaptive deep brain stimulation for movement disorders. Neurotherapeutics 16(1):105-118 
140. Jimenez-Shahed J, Telkes I, Viswanathan A, Ince NF (2016) GPi oscillatory activity differentiates tics from the resting state, voluntary movements, and the unmedicated Parkinsonian state. Front Neurosci 10:436

141. Hashemiyoon R, Kuhn J, Visser-Vandewalle V (2017) Putting the pieces together in Gilles de la Tourette syndrome: exploring the link between clinical observations and the biological basis of dysfunction. Brain Topogr 30(1):3-29

142. McGovern RA, Sheth SA (2017) Role of the dorsal anterior cingulate cortex in obsessive-compulsive disorder: converging evidence from cognitive neuroscience and psychiatric neurosurgery. J Neurosurg 126(1):132-147
143. Holtzheimer PE, Husain MM, Lisanby SH, Taylor SF, Whitworth LA, McClintock S et al (2017) Subcallosal cingulate deep brain stimulation for treatment-resistant depression: a multisite, randomised, sham-controlled trial. Lancet Psychiatry 4(11):839-849

144. Merkl A, Aust S, Schneider GH, Visser-Vandewalle V, Horn A, Kühn AA et al (2018) Deep brain stimulation of the subcallosal cingulate gyrus in patients with treatment-resistant depression: a double-blinded randomized controlled study and long-term follow-up in eight patients. J Affect Disord 227:521-529

145. Hartmann A (2016) Deep brain stimulation in Gilles de la Tourette syndrome: killing several birds with one stone? F1000Res $5: 2255$

\section{Authors and Affiliations}

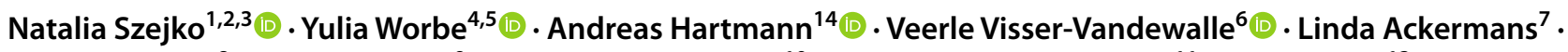

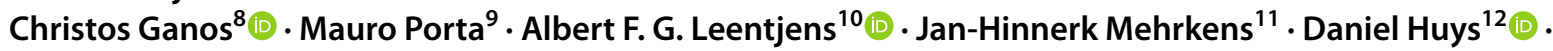 Juan Carlos Baldermann ${ }^{12}$ (D) Jens Kuhn ${ }^{12,13}$ (D) $\cdot$ Carine Karachi $^{5,14,15} \cdot$ Cécile Delorme $^{14}$ (D) Thomas Foltynie $^{16}$ (1) Andrea E. Cavanna ${ }^{17}\left[\right.$ D Danielle Cath ${ }^{18,19}$. Kirsten Müller-Vahl ${ }^{20}$}

1 Department of Neurology, Medical University of Warsaw, Banacha 1a, 02-091 Warsaw, Poland

2 Department of Bioethics, Medical University of Warsaw, Banacha 1a, 02-091 Warsaw, Poland

3 Department of Neurology, Yale School of Medicine, Yale University, New Haven, USA

4 Department on Neurophysiology, Saint Antoine Hospital, Sorbonne Université, Paris, France

5 National Reference Center for Tourette Disorder, Pitié Salpetiere Hospital, Paris, France

6 Department of Stereotactic and Functional Neurosurgery, Faculty of Medicine and University Hospital Cologne, University of Cologne, Cologne, Germany

7 Department of Neurosurgery, Maastricht University Medical Center, Maastricht, The Netherlands

8 Department of Neurology, Charité Universitätsmedizin Berlin, Berlin, Germany

9 Department of Neurosurgery and Neurology, IRCCS Instituto Ortopedico Galeazzi, Milan, Italy

10 Department of Psychiatry, Maastricht University Medical Center, Maastricht, The Netherlands

11 Department of Neurosurgery, Ludwig-Maximilians-University of Munich, Munich, Germany
12 Department of Psychiatry and Psychotherapy, University of Cologne, Cologne, Germany

13 Department of Psychiatry, Psychotherapy, and Psychosomatics, Johanniter Hospital Oberhausen, Oberhausen, Germany

14 Department of Neurosurgery, Pitié-Salpetriere Hospital, Sorbonne Université, Paris, France

15 Department of Neurology, Pitié-Salpetriere Hospital, Sorbonne Université, Paris, France

16 Department of Clinical and Movement Neurosciences, UCL Queen Square Institute of Neurology, London, UK

17 Institute of Clinical Sciences, University of Birmingham, Birmingham, UK

18 Department of Specialist Trainings, GGZ Drenthe Mental Health Institution, Assen, The Netherlands

19 Department of Psychiatry, University Medical Center Groningen, Rijks University Groningen, Groningen, The Netherlands

20 Clinic of Psychiatry, Social Psychiatry and Psychotherapy, Hannover Medical School, Hannover, Germany 